\title{
SEBASTIÁN LÓPEZ DÁVALOS, UN PINTOR NOVOHISPANO DEL SIGLO XVII
}

\author{
Rogelio RUIZ GoMAR
}

Entre los pintores activos en el virreinato de la Nueva España hacia el segundo tercio del siglo xvi, está Sebastián López Dávalos o de Ávalos, como indistintamente se le consigna.

Mencionado por casi todos los estudiosos que se han ocupado de la pintura novohispana, es, al mismo tiempo, uno de los artistas sobre los que menos información poseemos. Este aparente contrasentido se aclara cuando nos percatamos de que, si bien es cierto que le han consignado en sus obras Couto, el doctor Lucio, Bernardo Olivares, Revilla, Agustín Fernández Villa, Toussaint, Velázquez Chávez, Diego Angulo y Carrillo y Gariel, todos se han concretado prácticamente a repetir los mismos datos, cuando no a incluirlo, simplemente, en su "nómina" de pinceles coloniales.

Los escuetos datos que sobre López Dávalos poseemos, y que de autor en autor, desde Couto, se han venido repitiendo casi sin variantes, son los de que en el año de 1666 participó, junto con otros pintores de la época, en la primera inspección del milagroso ayate con la imprimación de la Virgen de Guadalupe, y de que es el autor de los cuadros con pasajes de la vida de los santos hermanos, médicos de profesión, Cosme y Damián, que luce el retablo de la capilla a ellos dedicada en la catedral de México. Eso es todo. $\mathrm{Y}$, sin embargo, bien mirado viene a ser bastante.

Su actuación profesional se reduce, pues, a dos intervenciones, pero a cual más relevanteś. La primera le mereció que su nombre fuese sistemáticamente recogido -junto con el de sus colegas-por la mayoría de los estudiosos de la Virgen de Guadalupe, desde el padre Francisco Florencia, a finales del siglo XVII, hasta Primo Feliciano Velázquez y Ernesto de la Torre en nuestros días, pasando por Cayetano Cabreray Quintero, Miguel Cabrera e Hipólito Vera. ${ }^{1}$

\footnotetext{
${ }^{1}$ Francisco Florencia, La Estrella del Nortede México, México, 1688; Cabreray Quintero, Escudo de Armas de México, México, 1746; Miguel Cabrera, Maravilla Americana y conjunto de raras maravillas, México, 1756; Fortino Hipólito Vera, Informaciones sobre la milagrosa aparición de la santísima Virgen de Guadalupe, recibidas en 1661 y 1723, Amecameca, 1889; Primo Feliciano Velázquez, La aparición de Santa María de Guadalupe (la ed. 1931), ed facsimilar, México, Editorial Jus, 1981, p 229, y Ernesto de la Torre Villar y Ramiro Navarro de Anda, Testimonios históricos guadalupanos, México, Fondo de Cultura Económica, 1982, p. 494.
} 
Y no era para menos, pues no hay que perder de vista que se trataba de la primera inspección que se hizo a tan venerada imagen.

En lo que toca a la segunda, es evidente que el hecho de que sus únicas obras hasta hoy conocidas se guarden en una de las capillas de la catedral metropolitana ha garantizado que también su nombre se consigne con frecuencia.

En efecto, en este artista han concurrido dos hechos fundamentales para que su nombre no se hubiese perdido: sus obras han estado siempre en un monumento insigne y a la vista de todos, y él, ligado a un hecho importante relacionado con la imagen más venerada de nuestra nación. Estas dos circunstancias explican, a mi manera de ver, el que su nombre hubiese sido recogido con mucha mayor frecuencia que el de otros pintores coloniales acaso de mayor valía.

$Y$ es que si tales cuadros suyos, pongamos por caso, estuvieran en el retablo de una modesta iglesia de Azcapotzalco o de Cholula, y la inspección que hizo hubiese sido, no de la Virgen de Guadalupe, sino del Cristo de Santa Teresa o del Señor de Chalma, es seguro que su nombre se hubiera perdido o sería bastante menos conocido aún. $Y$ es que, pese a todo, Sebastián López Dávalos es tan sólo uno más entre los "pintores secundarios" que florecieron hacia la segunda mitad del siglo XVII, según la siempre respetable sanción del gran estudioso de nuestra pintura colonial, don Manuel Toussaint. ${ }^{2}$

El propósito de este trabajo es, simplemente, el de intentar arrojar un poco de luz sobre este pintor, al aportar datos biográficos hasta ahora desconocidos, y el ofrecer una breve descripción y algunos comentarios sobre sus cuadros. Atiendo, pues, a lados oscuros del hombre y del artista, pues este último, aunque consignado, lejos está de haber sido estudiado.

Acaso emparentado con el impresor Diego López Dávalos, de principios del xvI ${ }^{3}$ Sebastián López Dávalos fue natural de la ciudad de Puebla, la segunda ciudad en importancia del periodo virreinal. Debió nacer alrededor del año 1615, dentro del matrimonio formado por Sebastián López Dávalos e Isabel Martínez de Andrada. Estos datos se desprenden de la partida de

\footnotetext{
${ }^{2}$ Pintura colonial en México, México, Universidad Nacional Autónoma de México, Instituto de Investigaciones Estéticas, 1965, cap. XVIII, p. 111.

${ }^{3}$ De su taller en el colegio de Tlatelolco salieron, entre 1604 y 1611, muchas obras, como los Coloquios espirituales de González de Eslava (1610). Al casarse con la hija de Antonio de Espinosa heredó el taller de éste, y si, como parece, le compró su taller a Melchor Ocharte, entonces llegaron también a sus manos las antiguas imprentas de Juan Pablos y Pedro de Ocharte. Al morir, su viuda tomó la dirección de la imprenta. Otro posible antepasado de nuestro pintor pudo ser el portugués Simón López Dávalos, que en marzo de 1626 contrajo matrimonio en la ciudad de México con Violante Méndez. Archivo del Sagratio Metropolitano, Libro 4 de matrimonios de españoles, 1621.1629, f. $59 \mathrm{v}$.
} 
amonestación que se anotó en el libro correspondiente cuando, a finales del año 1636, el pintor que nos ocupa pretendía contraer matrimonio con María de Medina Calderón. Por ser ésta natural de la ciudad de México, dichas amonestaciones corrieron en esta última ciudad a finales del mes de septiembre de ese año:

Sebastián Lópes de Abalos, natural de la ciudad de los Angeles, hijo de Sebastián Lópes de Abalos y de Isabel Martínez de Andrada, con María de Medina, natural de esta ciudad, hija de Fernando Calderón y de Ysabel de Medina ${ }^{4}$

y el matrimonio se verificó el 30 de septiembre de ese año en la misma ciudad de México. ${ }^{5}$ Ignoro cuál fue el motivo por el que transcurrieron seis años antes de que comparecieran a la ceremonia de "velación", pero al fin ésta se verificó el 4 de marzo de 1642 en el colegio de San Juan de Letrán. ${ }^{6}$

El hecho de que hubiesen sido bautizados en la parroquia de la catedral de México los hijos de su matrimonio, permite asegurar que López Dávalos terminó avecindándose en esta ciudad. A escasos diez meses de su boda, el 31 de julio de 1637 , fue llevado a bautizar el primogénito, Diego. ${ }^{7}$ A éste habrían de seguir de menos otros ocho hijos más: María, llevada a bautizar el 24 de diciembre de $1639 ;{ }^{8}$ Luis, el 3 de septiembre de 1642, de quien fueron padrinos el célebre pintor sevillano Sebastián López de Arteaga y Juana de Salinas, su mujer; ${ }^{9}$ Gregorio, el 26 de noviembre de $1644 ;^{10}$ Isabel, el 30 de octubre de $1649 ;^{11}$ Francisca, el 7 de octubre de $1651 ;^{12}$ Mariana, el 8 de marzo de 1655 , de la que figura como padrino Pedro Ramírez;, ${ }^{13}$ y los

${ }^{4}$ Archivo del Sagrario Metropolitano (en adelante citado: ASM), Libro 4 de amonestaciones de españoles, 1634-1640, f 32 v. Agradezco al Pbro. Rubén Ávila Enríquez y al señor Ricardo Gracida, párroco y administrador del Sagrario, respectivamente, las facilidades pr estadas para la consulta del rico archivo bajo su custodia.

${ }^{5}$ ASM. Libro 5 de matrimonios de españoles, 1629-1637, f. 130.

${ }^{6}$ ASM Libro 6 de matrimonios de españoles, 1637-1646, f. 219.

${ }^{7}$ ASM. Libro 13 de bautismos de españoles, $1634-1639, \mathrm{f} .247 \mathrm{v}$.

${ }^{8}$ ASM Ibidem, f. 453.

${ }^{9}$ ASM Libro 14 de bautismos de españoles, $1640-1643$, f $210 \mathrm{v}$.

${ }^{10}$ ASM Libro 15 de bautismos de españoles, 1644-1647, f. 72

$"$ ASM Libro 16 de bautismos de españoles, 1647-1652, f. 154.

${ }^{12}$ Sus padrinos fueron el acaso pintor Nicolás Becerra y doña Clara de Salas . ASM. Ibidem, f. 301 Esta Francisca (López Calderón) casaría a principios de 1683 con José de Per ea, huérfano: ASM Libro 12 de amonestaciones de españoles, 1680-1687, f $53 \mathrm{v}$

${ }^{13}$ ASM Libro 17 de bautismos de españoles, 1652-1655, f. 217 v. A menos que sea un homónimo, es probable que se trate de Pedro Ramírez "el viejo", maestro ensamblador, escultor y arquitecto. Difícilmente pudo ser el pintor Pedro Ramírez "el mozo", pues éste apenas iba a cumplir 17 años, toda vez que habia nacido en septiembre de 1638 . 
mellizos Nicolás y Antonio, el 26 y 27 de junio de $1660 .{ }^{14} \mathrm{~A}$ los anteriores habría que agregar a Isidro López Dávalos, de quien, pese a que no se ha localizado la partida de bautismo correspondiente, él mismo declaró, al pretender contraer matrimonio con María de la $\mathrm{O}$, a finales de 1681, que eran sus padres el pintor que nos ocupa y su mujer. ${ }^{15}$

Tras enviudar, Sebastián López Dávalos pasó a segundas nupcias. En abril de 1664 corrieron las amonestaciones del enlace que pretendía con Gertrudis de Quiñones ${ }^{16}$ mas algo debió ocurrir, pues en julio de ese mismo año corrieron las amonestaciones para su enlace con otra mujer, María de Arnao, natural de Zacatecas y vecina de la ciudad de México "de veinte años a esta parte" ${ }_{17}^{17}$ con quien efectivamente casó un mes después. ${ }^{18}$

La última noticia que sobre él poseemos es la de que el 5 de noviembre de 1679 aparece junto con su mujer como padrinos de bautizo de la niña Francisca, hija de Felipe Alfonso de Sandoval y doña Francisca Sandoval. ${ }^{19}$ Tendría el pintor para entonces aproximadamente unos 65 años.

Desconocemos la fecha exacta en que murió, pero en el acta de defunción de su segunda mujer, en mayo de 1694, ya se le consigna como viuda. ${ }^{20}$

Tras haber agotado las noticias que hemos ido reuniendo referentes al hombre, vengamos con el artista.

Empecemos con un dato dado a conocer en fecha muy reciente y que viene a confirmar el lazo de amistad que le unía con el afamado pintor sevillano López de Arteaga, a quien ya vimos llevar a la pila bautismal a uno de sus hijos. En 1652 López Dávalos figura como testigo en uno de los documentos relacionados con la infortunada muerte de Arteaga. ${ }^{21}$

\footnotetext{
${ }^{14}$ ASM. Libro 20 de bautismos de españoles, 1660-1663, f. 3 v. Del primero fue padrino el licenciado Ignacio Lagarto de la Vega. Este Nicolás López de Ávalos contrajo matrimonio en julio de 1699 con Juana Marcela de Cárdenas: ASM Libro 14 de amonestaciones de españoles, 16941701, f. 100 v. y ASM. Libro 13 de matrimonios de españoles, 1694-1701, f. 201. Al segundo lo encontramos queriendo casarse a principios de 1683 con Gertrudis del Castillo, ASM Libro 12 de amonestaciones ..., f. $58 \mathrm{v}$. Al enviudar casó con Tomasa Ortega, en agosto de 1686: ASM. Libro 11 de matrimonios de españoles, 1680-1687, f. 294.

${ }^{15}$ ASM Libro 12 de amonestaciones de españoles, 1680-1687, f, 27. Micaela Dávalos, una hija de este matrimonio, pretendía casarse con Francisco Ruiz en 1712: ASM Libro 16 de amonestaciones de españoles, 1706 1714, f 135 . El propio Isidro López Dávalos pasó a segundas nupcias con Juana de la Rosa Herrera (viuda de Manuel de Herrera) en octubre de 1718: ASM Libro 17 de amonestaciones de españoles, 1714-1719, f. 120 v. Maxía Joaquina, hija de este último enlace, casaria en febrero de 1725 con Domingo Mendoza: ASM. Libro 18 de amonestaciones de españoles, 1719-1727, f $141 \mathrm{v}$.

${ }^{16}$ ASM. Libro 9 de amonestaciones de españoles, 1662-1666, f. 38 .

${ }^{17}$ ASM Ibidem, f. 43

${ }^{18}$ La boda fue el 10 de agosto de 1664: ASM. Libro 8 de matrimonios de españoles, 1657-1667, f. 215. En anotación marginal se asevera que la velación se verificó el 9 de enero de 1667 .

${ }^{19}$ ASM. Libro 26 de bautismos de españoles, 1679-1682, f. 62

${ }^{20}$ ASM. Libro 4 de defunciones de españoles, 1693-1696, f 81 v. Vivía en la calle de la Acequia.

${ }^{21}$ Vide. Xavier Moyssén, "Sebastián de Arteaga (1610-1652)", en Anales del Instituto de
} 
Igualmente, dato poco conocido y que en cierta medida viene a poner en relieve el destacado papel que jugó Sebastián López Dávalos en el desarrollo de la pintura de su época, es el concerniente al "poder" que nuestro pintor y Cristóbal Caballero recibieron de parte de los demás maestros de ese arte, en agosto del año de 1674, "para que en sus nombres y representando sus personas puedan parecer y parezcan ante cualesquier justicias, tribunales eclesiásticos y seculares...y sigan, fenezcan y acaben por todas instancias y sentencias el dicho pleito y causa."22

El documento no aclara qué clase de "pleito" era en el que estaban envueltos los pintores, pero a juzgar por la cercanía de la fecha, no sería difícil que tuviera que ver con el deseo de revitalizar el "gremio de pintores y doradores", merced a la obtención de nuevas "Ordenanzas" que garantizaran el correcto desempeño del mismo, lo cual habrían de alcanzar poco después, en $1687 .{ }^{23}$

Sea como fuere, podemos inferir que López Dávalos y Cristóbal Cáballero gozaban de buena reputación ante sus colegas, pues de otra manera no se entiende que confiaran en ellos para algo que parecía delicado. Once pintores son los que suscriben el documento: Antonio Sarmiento Girón, José de Villegas, Sebastián de Barahona, Miguel Becerra, Juan Sánchez Salmerón, Antonio Rodríguez, Juan Correa, Lorenzo de la Piedra, Miguel Gil de Arévalo y Jerónimo de Rojas; pero el que se haya expresado "por lo que les toca y por los demás maestros que son de dicho arte", deja fuera de duda que iban en realidad en representación de todos los pintores activos en la ciudad de México. ${ }^{24}$

Pasemos ahora a la participación de López Dávalos en la inspección que, junto con otros afamados pintores de la época, hiciera de la imagen de la Virgen de Guadalupe. Con el fin de dotar de base más sólida la petición elevada por don Diego Osorio Escobar y Llamas ante el Papa Alejandro VII de que se considerara día festivo el $1 \hat{2}$ de diciembre y de que concediera rezo propio para la Virgen de Guadalupe en el "oficio divino", se realizaron en el año de 1666 -a una distancia de 135 años del suceso- informaciones

\footnotetext{
Investigaciones Estéticas, vol. xv, núm. 59, México, Universidad Nacional Autónoma de México, 1986, p. 24.

${ }^{22}$ Archivo General de Notarías de la ciudad de México Notaría 61 , a cargo de Nicolás Bernal. 10 de agosto de 1674, f. 117-118. Cfr. Rogelio Ruiz Gomar, "El gremio de pintor es y doradores", en Elisa Vargaslugo y Gustavo Curiel, Juan Correa. Su vida y su obra, México, Universidad Nacional Autónoma de México, Instituto de Investigaciones Estéticas, 1992.

${ }^{23}$ En 1681 obtuvieron los pintores un traslado de las antiguas. Ordenanzas; a partir de ellas elaboraron las nuevas, que fueron autorizadas y promulgadas en 1687.

${ }^{24}$ Aparece como testigo "el bachiller Felix Suárez, clérigo de ordenes menores", acaso Félix Juárez, hijo del ya finado pintor José Juárez.
} 
jurídicas en torno a la autenticidad de las apariciones y de la milagrosa estampación. ${ }^{25}$

Para tal ocasión se convino en convocar a un grupo de pintores para que dieran su parecer acerca de la imagen desde el punto de vista artístico. Así, junto a los testimonios de los indios viejos de Cuauhtitlán y de los varones graves de México, fue solicitado el voto de maestros en la pintura.

Recayóla elección en siete pintores: JuanSalguero, Tomás Conrado, Nicolás de Fuenlabrada, Sebastián López Dávalos, Nicolás de Angulo, Juan Sánchez (¿Salmerón?) y Alonso de Zárate, entendidos como "personas de toda inteligencia y de las más peritas en el arte". Dichos maestros habían visto la imagen infinitas veces, pero entonces la reconocieron tanto por el haz como por el envés, y admirando su disposición, partes tan bien distribuidas del cuerpo, trazos y arte del ropaje, llegaron a la conclusión de que "no ha de haber pintor, por diestro que sea y muy bueno, como los ha habido en esta Nueva España, que acierte a imitar perfectamente el colorido". Asimismo, en relación a la técnica empleada, no alcanzaron a determinar si era al temple o al óleo,

porque parece lo uno y lo otro...; porque Dios nuestro Señor solamente sabe el secreto de esta obra y la perpetuidad de su conservación, en la fortaleza y permanencia de sus lindos colores y dorado de las estrellas, labores y orla de la vestidura y tez de la pintura, que parece está acabada de hacer, con la hermosísima encarnación del rostro y manos. ${ }^{26}$

El primer autor que refiere todo lo relativo a esta primera inspección de pintores y nos recuerda el nombre de ellos fue el jesuita Francisco de Florencia, en su conocido texto La Estrella del Norte, quien nos informa que eran todos examinados, aprobados y ejercitados con crédito y aplausos muchos años ${ }^{27}$ Tiempo después haría otro tanto Cayetano Cabrera Quintero:

Fue la primera concurrencia de pintores, de los más diestros, que ha solido criar, o se han transplantado a nuestro México, cuyas obras aún nos están diciendo sus aciertos; alguno clérigo presbítero, como el licenciado Juan Salguero, otros de letras, como el bachiller Tomás Conrado; los otros de más obras que palabras, como Nicolás de Fuenlabrada, Sebastián López de Avalos, Nicolás de Angulo, Juan Sánchez, Alonso de Zárate..

${ }_{25}^{25}$ Escobar y Llamas era obispo de Puebla, gobernador del arzobispado de México y virrey de la Nueva España.

${ }^{26}$ Asimismo, advirtieron la imposibilidad de poner aparejo y pintar sobre lo áspero de la tilma. Y tras estudiarla por el revés y ver que se transparentaba la imagen, concluyeron con gran admiración que "no tiene aparejo ninguno, ni imprimación el dicho lienzo, más que el cuerpo que los mismos colores le dieron, tupidos e incorporados con los hilos toscos del dicho lienzo..." Informaciones de 1666, publicadas por Fortino Hipólito Vera, Amecameca, 1889, pp. 137 y 133.

${ }^{27}$ La Estrella del Norte de México, México, 1688, cap. 13, parágrafo 4, p. 60. 
los cuales, continúa:

por mandato del V. deán y cabildo, en presencia hasta del excelentísimo señor virrey, marqués de Mancera, hicieron el prolijo examen que ocupa cinco fojas al proceso, y dijeron generalmente no haber podido hallar, ni descubrir en la pintura de la sacratísima imagen cosa que no sea misteriosa y milagrosa; y que otro que Dios Nuestro Señor no pudo obrar cosa tan bella y de tantas perfecciones. ${ }^{28}$

Poco tiempo después el celebérrimo Miguel Cabrera habría de participar en otra inspección de la milagrosa imagen del Tepeyac. En el opúsculo que redactó como resultado de sus observaciones no podía menos que hacer referencia a la anterior inspección calificando a los artífices que participaron en aquella ocasión como "...los más excelentes pintores" .29

De renombre en su época, con el tiempo algunos de dichos pintores cayeron en el olvido. Por ello don José Bernardo Couto se apresura a expresar: "Yo no he visto hasta ahora de todos ellos, sino unos cuadros apaisados del Avalos", ${ }^{30}$ los cuales, como veremos a continuación, son precisamente los del retablo de la capilla de Cosme y Damián en la catedral de México.

Pasemos ahora a la intervención de López Dávalos en las pinturas que decoran el mencionado retablo de los santos Cosme y Damián en la catedral metropolitana. ${ }^{31}$

Couto apunta que son "cuadros apaisados", que están "en el altar de la testera de la capilla de San Cosme en Catedral", y termina diciendo que "son poca cosa a juicio de los inteligentes". Opinión que hace que don Manuel Toussaint aclare en una nota: "No son apaisados ni de tan escasa consideración como juzga Couto." " 2

El canónigo don Pablo de Jesús Sandoval precisó que el artista firmó en dos cuadros: en el pequeño, del lado del evangelio, en la filacteria que sostiene un águila ("Sebastián López Dávalos fet"), y en el lienzo grande del segundo cuerpo de ese mismo lado ("Dávalos fet"); asentó que son "seis cuadros con marcos antiguos de gran relieve, estofados de negro y oro", y que eran "de gran mérito y actualmente gran valor y precio" ".

${ }^{28}$ Cayetano Cabrera Quintero, Escudo de Armas .... México, 1736, Libro 3, capítulo 12, parágrafo 619 , pp. 311-312.

${ }^{29}$ Maravilla Americana..,, México, 1756, pp. 28-29

${ }^{30}$ José Bernardo Couto, Diálogo sobre la historia de la pintura en México, ed., pról. y notas de Manuel Toussaint, México, Fondo de Gultura Económica, 1947, p. 74.

${ }^{31}$ Por confusión, don Diego Angulo Íñiguez señaló que se trataba de "medianas pinturas en San Cosme"; Historia del arte hispanoamericano, Barcelona, Salvat, 1951, t. II, cap. XI, p. 424.

${ }^{32}$ Couto, op cit., p. 74

${ }^{33}$ Pablo de Jesús Sandoval y José Ordoñez, La catedral metropolitana de México, México, Victoria, 1943, p. 88 
Por su parte, don Agustín Velázquez Chávez señaló que "son ocho lienzos que pintan la ejecución del martirio de los santos doctores Cosme y Damián", y añadió: "El valor pictórico de estas obras, que no deben ser olvidadas en la historia de nuestra pintura, acaso no haya sido debidamente reconocido por la dificultad que hay para apreciarlas en el lugar en que se encuentran y tal vez porque el barniz las ha enegrecido", ${ }^{34}$ juicio que nos parece de sumo interés y que vale la pena retener por cuanto que alude a una situación que se mantiene hasta nuestros días: no obstante ser cuadros registrados, en realidad no han sido estudiados.

Antes de pasar a la descripción y análisis de dichos cuadros, convendría abrir un pequeño paréntesis para referimos a la capilla de los santos Cosme y Damián y recordar lo más importante de la vida de este par de hermanos. Por lo que toca a la capilla, lo primero que habría que decir es que, la verdad, es muy poco lo que se sabe en relación con ella. No sólo se desconocen los datos fundamentales en torno a su origen, sino que, a diferencia de lo que sabemos de la mayoría de las demás capillas de la catedral, tal pareciera que no albergó prestigiosas reliquias, ni poseyó indulgencias especiales, ni ahí fue sepultado nadie importante. Es por ello que don José María Marroqui, el infatigable cronista de la ciudad de México, en el paso del siglo xix al actual, confesara: "De esta capilla nada hemos podido encontrar." 35

En efecto, esta capilla -la segunda del lado del Evangelio, o lado izquierdo, contando desde los pies de la fábrica- ha sido una de las que han recibido menos atención de cuantos se han ocupado del edificio catedralicio desde el mismo periodo colonial.

La capilla quedó encomendada a la hermandad del gremio de gorreros y sederos alrededor del año de 1660 en que, al parecer, se cerró la bóveda de la misma, siendo uno de los últimos espacios catedralicios en quedar. habilitado ${ }^{36} \mathrm{El}$ porqué se dedicó a los santos Cosme y Damián no está claro, pero conviene recordar que la devoción al par de hermanos médicos en la Nueva España viene desde el siglo XvI, como se desprende de que a ellos estuviera dedicada la ermita que en 1526 se comprometieron a erigir los sastres, o de que el Hospital del Amor de Dios que fundara fray Juan de Zumárraga en 1541 estuviera puesto bajo su protección. ${ }^{37}$

Por lo que toca a los santos Cosme y Damián, es preciso asentar, asimismo, que son muy escasas las noticias con que se cuenta de ambos, y las más de

${ }^{34}$ Tres siglos de pintura colonial, México, Ed. Polis, 1939

${ }^{35}$ La ciudad de México, t. III, p. 457

${ }^{36}$ Rogelio Ruiz Gomar, "Capilla de San Cosme y San Damián", en Catedral de México. Patrimonio artístico y cultural, México, Secretaría de Desarrollo Urbano y Ecología, 1986, p. 183.

${ }^{37}$ Ibidem, p. 182 
ellas carecen de valor histórico o resultan confusas. ${ }^{38}$ Lo generalmente aceptado es que eran hermanos gemelos que nacieron en Arabia, en el seno de un hogar cristiano; que después de estudiar medicina en Siria, ejercieron dicha profesión en Asia Menor sin aceptar ninguna remuneración. Que como confesaran abiertamente su adhesión a la doctrina cristiana, fueron de los primeros en ser aprehendidos cuando empezó la persecución, y que Lisias, el procónsul o gobernador de la región, les sometió a diversos tormentos antes de sentenciarlos a morir decapitados . Sus restos fueron conducidos a Siria, que pronto se convirtió en centro principal de su culto, alcanzando gran veneración en Oriente y Occidente. Félix IV, en 530, trasladó a Roma sus reliquias y les levantó una basílica en la Vía Sacra, que es de título cardenalicio. Con el tiempo, sus reliquias se distribuyeron entre varias ciudades europeas ${ }^{39}$

Considerados la oposición cristiana de Cástor y Pólux, pronto las leyendas adornaron la sencilla historia de este par de hermanos con numerosas maravillas. Así, se dice que Lisias, después de haberlos capturado, mandó buscar a sus otros tres hermanos (Antonio, Leoncio y Euprepio) y, una vez reunidos los cinco, les ordenó ofrecieran sacrificios a los dioses. Como se negaran firmemente a ello, les sometió a diversos tormentos en su afán de hacerles renegar de su fe. Primero, de acuerdo con las leyendas tejidas a su alrededor y con la tradición recogida por Santiago de la Vorágine, les mandó machacar las manos y los pies. Como no consiguiera su objetivo, les mandó amarrar a unas piedras de molino y arrojar al mar, pero los ángeles cortaron las amarras y las olas los volvieron ilesos a la playa. Asombrado, Lisias les iba a soltar, pero como fuera abofeteado por dos demonios, se enfureció y mandó les echaran dentro de una enorme hoguera; pero las llamas respetaron a los cinco hermanos, no así a varios de los que habían acudido curiosos a presenciar el tormento, que fueron alcanzados y abrasados por las llamas.

Seguidamente les sometió al tormento del potro; pero también fue en vano, pues un ángel les protegió. Enitonces ordenó que los tres hermanos fuesen encarcelados y que Cosme y Damián fuesen apedreados. Mas cuando el pueblo empezó a arrojarles piedras, éstas se volvieron contra los que las arrojaban, quedando varios heridos. Lisias, furioso, mandó traer a los otros

${ }^{38}$ Así, por ejemplo, en Bizancio se honraba a tres pares de santos con el mismo nombre: unos de Arabia, decapitados durante la persecución de Dioclesiano; otros de Roma, que murieron apedreados en el curso del reinado de Carino, y otros que murieron tranquilamente. Vid. Alban Butler, Vidas de los Santos de Butler, trad. Wilfredo Guinea, S.J., 3a. ed, 4 vols., México, Colliers's International-John W. Clute, 1969; t. III, p. 684 .

${ }^{39}$ Ibidem y Enciclopedia Universal Ilustrada, Madrid, Espasa-Calpe, 1958, t. 15, p. 1140. 
tres, y a los cinco les hizo crucificar y ordenó fuesen acribillados a flechazos. Los saeteros obedecieron, pero ni un solo dardo se clavó en los hermanos, sino que todas las flechas, en cuanto salían de las cuerdas, se volvían con fuerza contra los que las habían lanzado y se hincaban en sus cuerpos. Lisias, confuso y furioso, dispuesto a terminar de una buena vez con la resistencia de aquellos valientes, ordenó que les cortaran la cabeza. ${ }^{40}$ Todo ello habría ocurrido a principios del siglo rv d.C., en tiempos de Dioclesiano, quien se significó por su crueldad contra los cristianos.

Del mismo modo se habla de innumerables milagros, sobre todo curaciones maravillosas, obradas por los mártires después de su muerte. Por ello es que son considerados, junto con san Lucas y san Pantaleón, patronos de médicos, cirujanos, boticarios y barberos. Su fiesta se celebra el 26 de septiembre.

Pero regresando al retablo de la capilla a este par de santos dedicada en la catedral, tenemos que es de estilo barroco con reminiscencias manieristas. Es una estructura de madera tallada y dorada de buenas proporciones y excelente trabajo. Está compuesto de banco, tres cuerpos y un pequeño remate, y organizado en tres calles, de las cuales la central queda realzada por pares de columnas estriadas de capitel corintio en los dos primeros cuerpos -salientes las que dan al centro-, mismas que se sustituyen por pilastras cariátides en el tercero.

La claridad compositiva en la retícula ortogonal que impera, el tipo de soportes, lo fino de la talla en los enmarcamientos y entablamentos, la base negra que aviva el dorado y perfila las formas arquitectónicas, así como el acento manierista de la decoración, son elementos que indican que se trata de una obra construida poco después de mediados del siglo xvil, de lo que resulta que es el retablo más antiguo de los que subsisten en la catedral. ${ }^{41}$

En el año de 1963 el retablo fue objeto de varias modificaciones llevadas a cabo por el señor Miguel Ángel Soto y sus hijos. Entre los cambios más notables se pueden mencionar la sustitución de la mesa del altar; el añadido del banco y varias reformas en la caile central: sustitución de un vitral con la Virgen de Guadalupe por la ventana con vidrios ámbar actual, la supresión del fanal central, la eliminación de una pintura de perfil mixtilíneo, ${ }^{42}$ y la colocación ahí de la pintura que representa a Nicolás V ante el cuerpo de San

\footnotetext{
${ }^{40}$ Santiago de la Vorágine, La leyenda dorada, trad. Fr. José Manuel Macías, 2 vols., Madrid, Alianza Editorial; t II, cap CXLIII, pp. 616-617.

${ }^{41}$ Gonzalo Obr egón, "Retablos de la catedral de México", en Artes de México, año XXI, núms $182-183$, p. 85

${ }^{42}$ Seguramente la representación de la Santísima Trinidad de Miguel Cabrera de que hablan algunos autores (Rivera Cambas, México pintoresco ..., t. I, p. 56; Marroqui, t. III, p 457; Pablo de Jesús Sandoval, p. 88; Toussaint, La catedral..., p. 153)
} 
Francisco, misma que hasta ese momento se encontraba en el encasamento del lado derecho de la capilla.

Destacan en él diez pinturas, siete de medianas dimensiones y otras tres de formato más pequeño, que representan, en su mayoría, pasajes de la vida de los santos titulares de la capilla.

Con la excepción del mencionado cuadro que representa el hallazgo del cuerpo incorrupto de san Francisco, recientemente colocado en el retablo, y que definitivamente no corresponde al ciclo, las nueve pinturas restantes fueron ejecutadas por López Dávalos, el artista que nos ocupa, y se trata de obras en tela pegada sobre madera.

Las dos pinturas de la predella tienen desarrollo horizontal y miden 54 x $145 \mathrm{~cm}$, cada una. La del lado izquierdo parece aludir a una escena de agradecimiento por alguna intervención milagrosa operada por el par de hermanos. La escena transcurre al exterior. En el espacio que queda entre varias casas están Cosme y Damián con un hombre cuya indumentaria refleja posición económica acomodada, y un siervo de éste. Los hermanos y el señor elevan la mirada, como agradeciendo a Dios alguna curación de la que parece ha sido testigo el azorado sirviente. Hacia los extremos, dos trozos de notable frescura, por lo que tienen de tono costumbrista: en el del lado izquierdo, unos aldeanos a la puerta de una casa han distraído brevemente sus tareas para ver lo que ocurre; en el otro, a la puerta de una maciza construcción, un perrillo se para sobre sus patas traseras para tratar de alcanzar al águila que vuela poco más alto y con cuyo pico sujeta la filacteria en que ha firmado el pintor ("Sebastián López Dávalos, fet").

La pintura en la predella del lado derecho representa uno de los más difundidos milagros obrados por Cosme y Damián, quienes, tras haberle amputado la pierna a un hombre, le transplantaron la de un moro que había muer to ese mismo día ${ }^{43} \mathrm{La}$ escena se desarrolla en una habitación que se abre a un corredor. A causa de lo alargado de la tabla y para centrar la atención, el pintor ha tenido que recurrir al artilugio de subdividir la composición en tres zonas; para ello ha echado mano de un par de sobrias pilastras tablereadas, y ha dejado los espacios laterales como zonas neutras. A fin de despejar toda duda respecto al pasaje en cuestión, el pintor ha incluido el cadáver del moro que "donó" la pierna, mismo que se encuentra tendido sobre un petate a los pies de la cama, y ha representado al hombre al que le ha sido transplantada la pierna, sentado en la cama, con la colcha roja

\footnotetext{
${ }^{43}$ El hombre en cuestión, de acuerdo con la leyenda recogida en La leyenda dorada por Santiago de la Vorágine, era el encargado de la limpieza en el templo que el Papa Félix había construido en Roma en honor de los santos hermanos; op cit, t.II, cap. CXI.III, pp 617-618.
} 
recogida para dejarnos ver el par de piernas, una de tez blanca y obscura la otra, agradeciendo a Dios la exitosa intervención obrada por los hermanos.

Siguen cuatro pinturas que describen algunos de los tormentos a que fueron sometidos, mismas que se alojan en las calles laterales de los dos primeros cuerpos del retablo $(205 \times 145 \mathrm{~cm})$. El cuadro derecho del primer registro ilustra el momento en que los dos hermanos comparecen ante Lisias después de que éste les había condenado a ser arrojados al mar atados a enormes piedras de molino, prueba de la que ya han salido indemnes, pues un ángel les desató y fueron devueltos por las olas a la playa.

Lisias se encuentra en alto sitial, rodeado de cortesanos y soldados. En sus rostros reflejan asombro y malestar, al ver que los hermanos han salido victoriosos de la prueba. Uno de los santos se ha arrodillado, agradecido, mientras el otro parece explicarle a un sayón lo que ha sucedido. Casi oculto, a las espaldas de éste, se observa al ángel que les ha salvado o a un mozo mostrando a Lisias cuán ineficaz han resultado nudos y cuerdas. En el ángulo inferior derecho se alcanza a ver la piedra de molino, así como varios caracoles esparcidos por el suelo. Al fondo, un delicado paisaje en el que serpentea un plácido río, a cuya orilla opuesta se levantan algunas construcciones.

En el cuadro del ladoizquierdo aparecen Cosme y Damián atados a sendas cruces, mientras varios hombres les arrojan piedras y disparan contra ellos flechas; pero, tal y como cuenta la leyenda, algunos proyectiles y saetas han invertido sus trayectorias antes de tocar siquiera el cuexpo de los hermanos, y amenazan con herir a los propios agresores.

En el cuadro del lado derecho del segundo registro se ilustra el momento en que el par de hermanos son desatados por un ángel y ante el estupor de Lisias y los demás testigos salen ilesos de las llamas.

En el del lado izquierdo se ha representado, finalmente, su decapitación. Uno de los hermanos yace con un tajo en el cuello, mientras que el otro, de rodillas y con la mirada dirigida hacia lo alto, espera el golpe final. Hacia la zona superior, unos angelitos descienden por una entrada de gloria, portando coronas de flores y la palma que alude al triunfo que los hermanos han obtenido por perseverar en la fe.

Los dos cuadros que flanquean la ventana en el tercer cuerpo representan a otros dos santos mártires $(185 \times 125 \mathrm{~cm})$. El del lado derecho es San Sebastián, aquel soldado romano que fuera asaeteado por negarse a rendir homenaje a los dioses paganos. Creyéndole muerto, fue arrojado su cuerpo a la cloaca, de donde le rescató santa Irene, quien cuidó de él en su convalecencia. Una vez repuesto, el propio Sebastián compareció de nuevo ante las autoridades, y fue sentenciado a morir decapitado, igual que los 


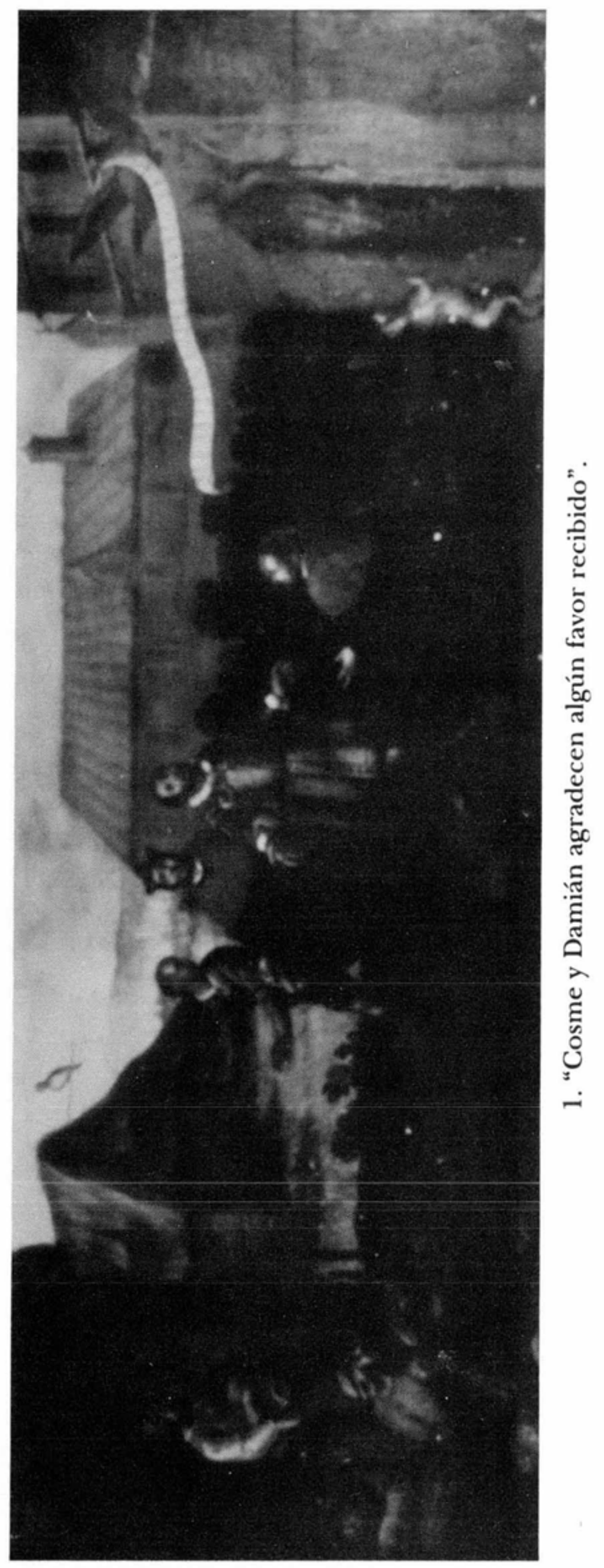




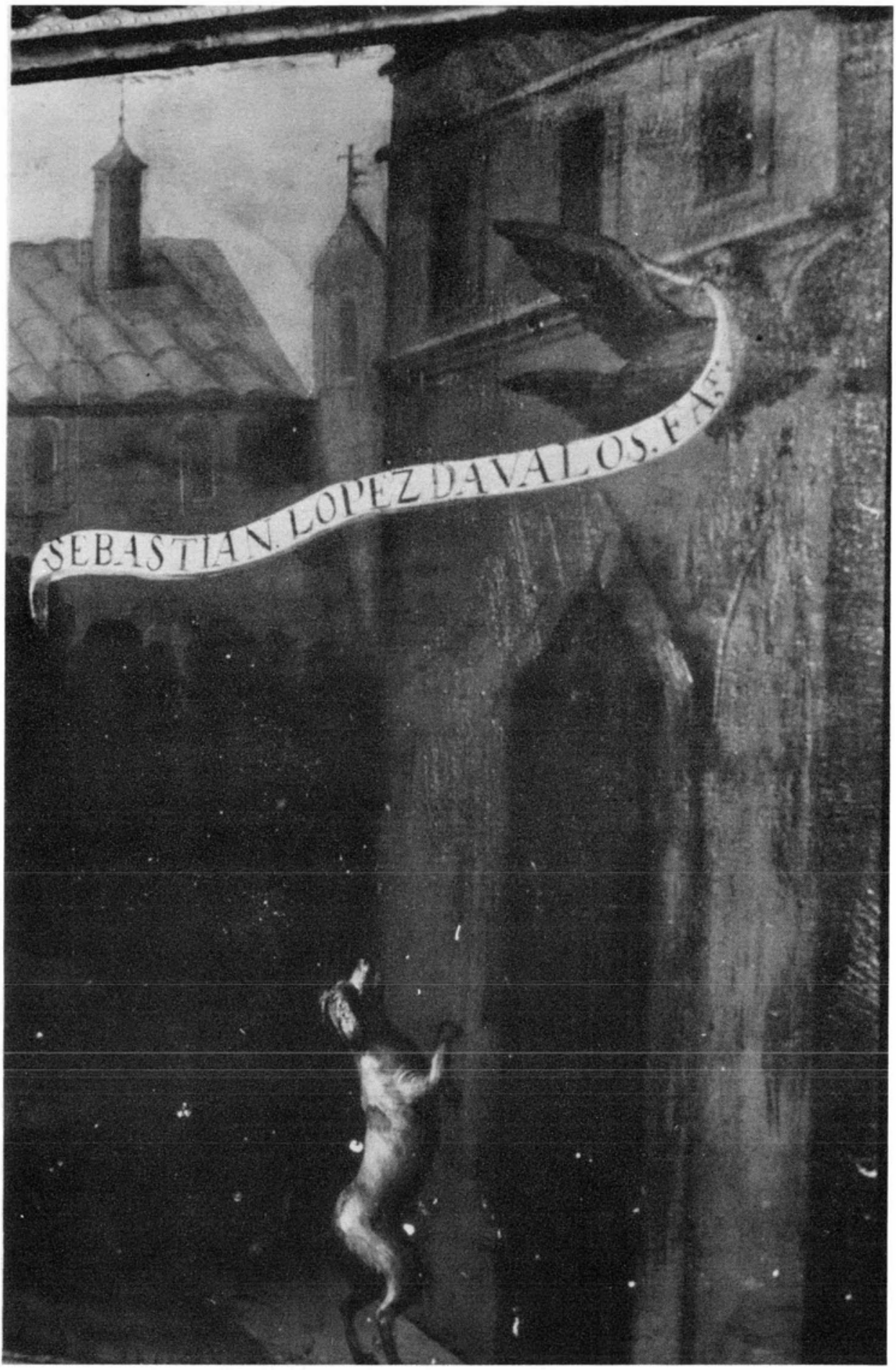

2. Detalle del cuadro anterior con la firma de Dávalos. 


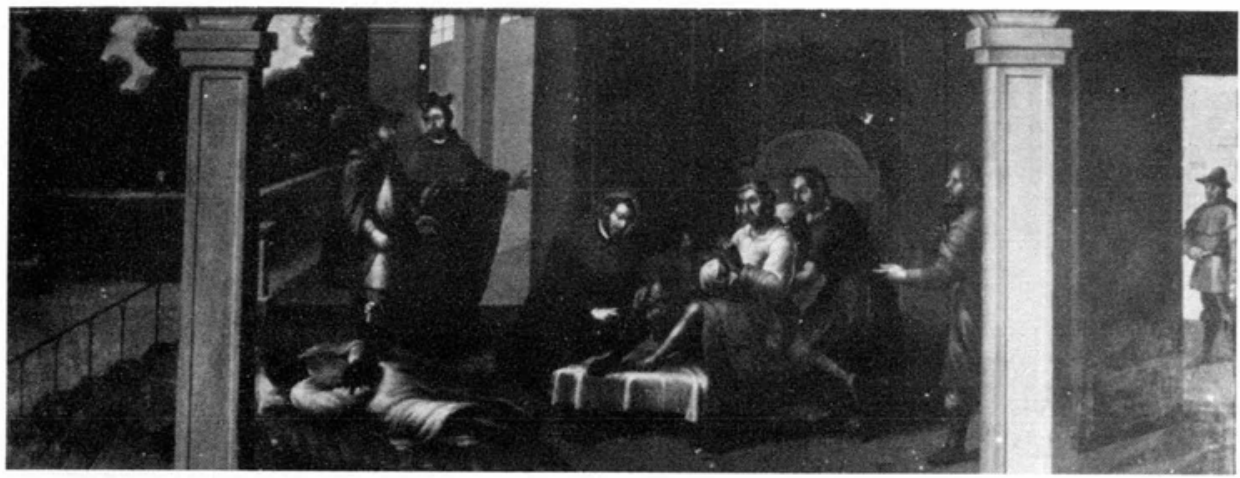

3. "El milagro del transplante de la pierna".

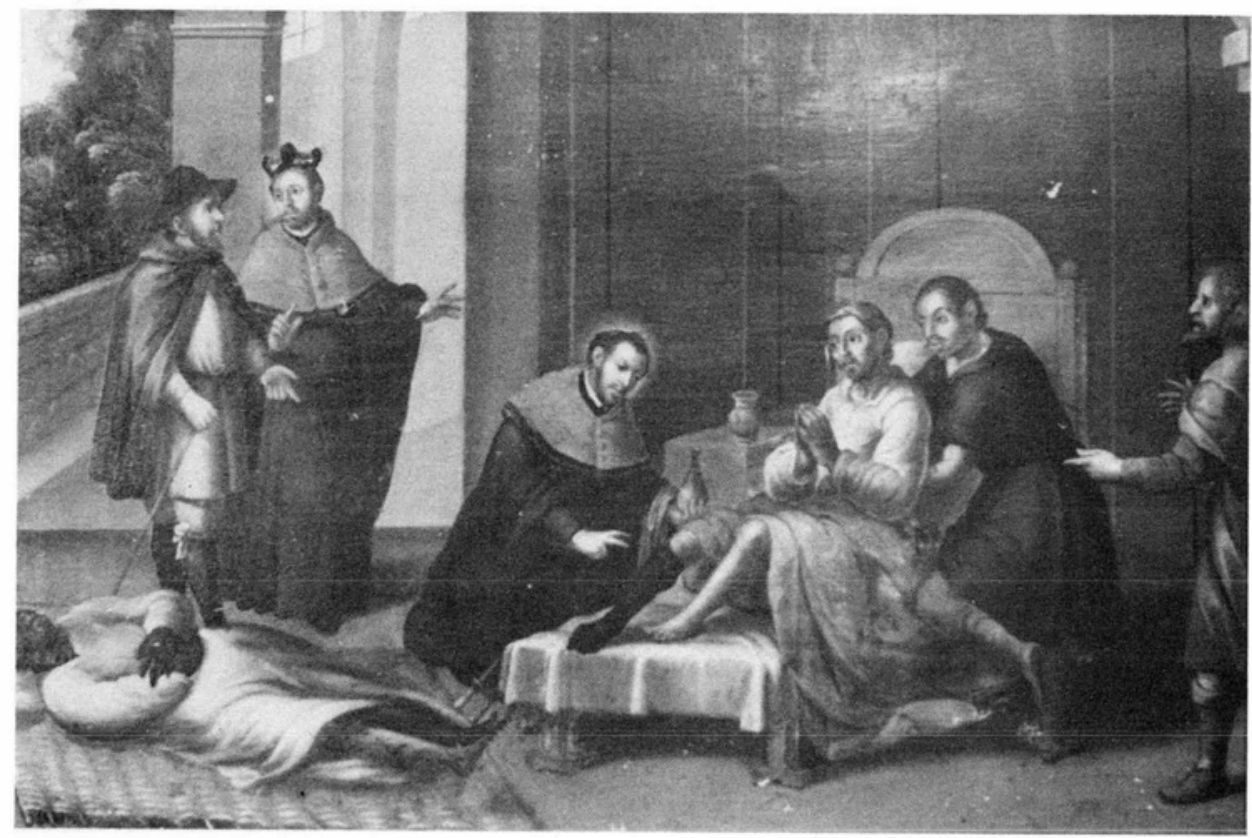

4. Detalle del cuadro anterior. 


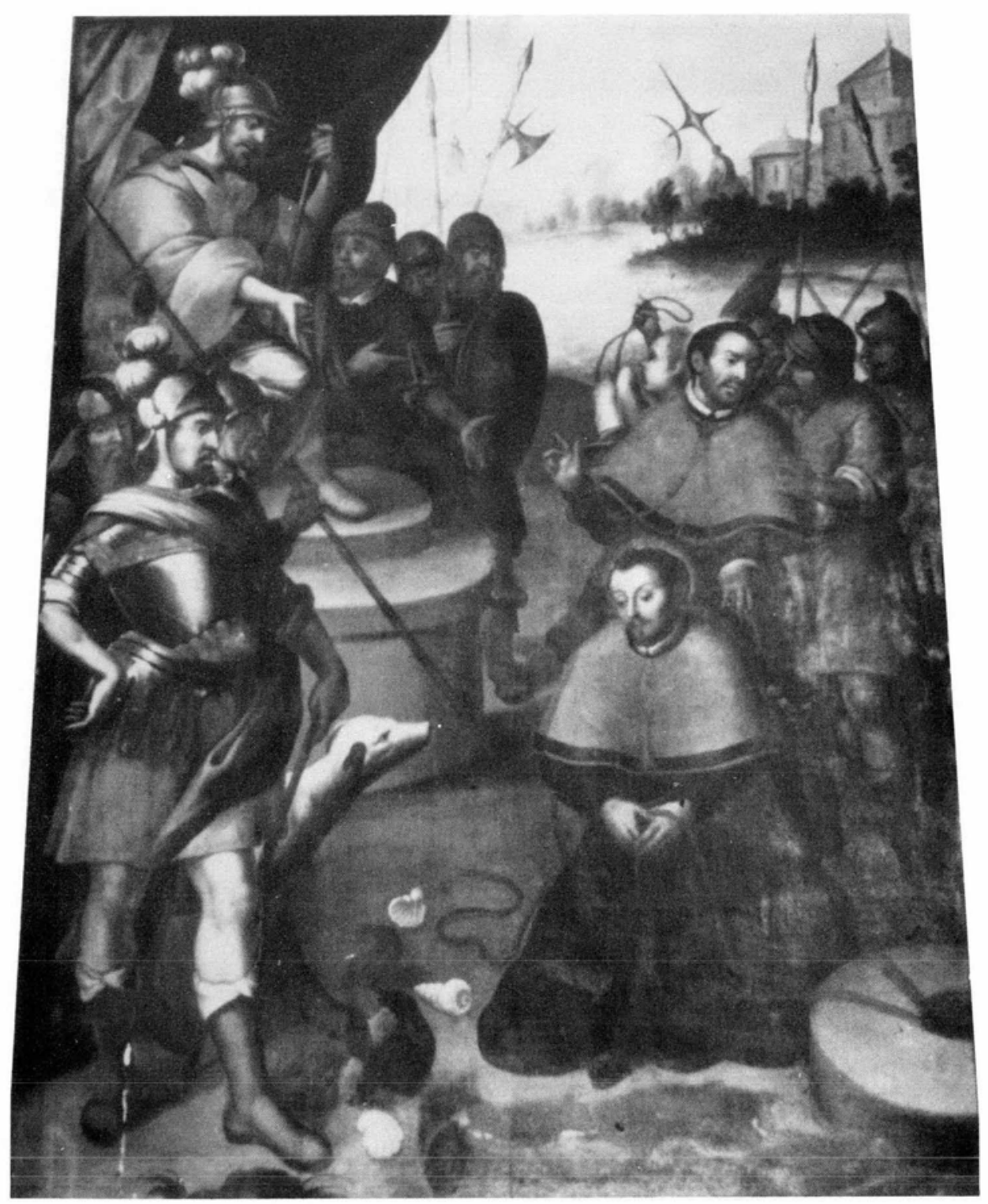

5. "Cosme y Damián regresan ilesos después de haber sido arrojados al mar". 


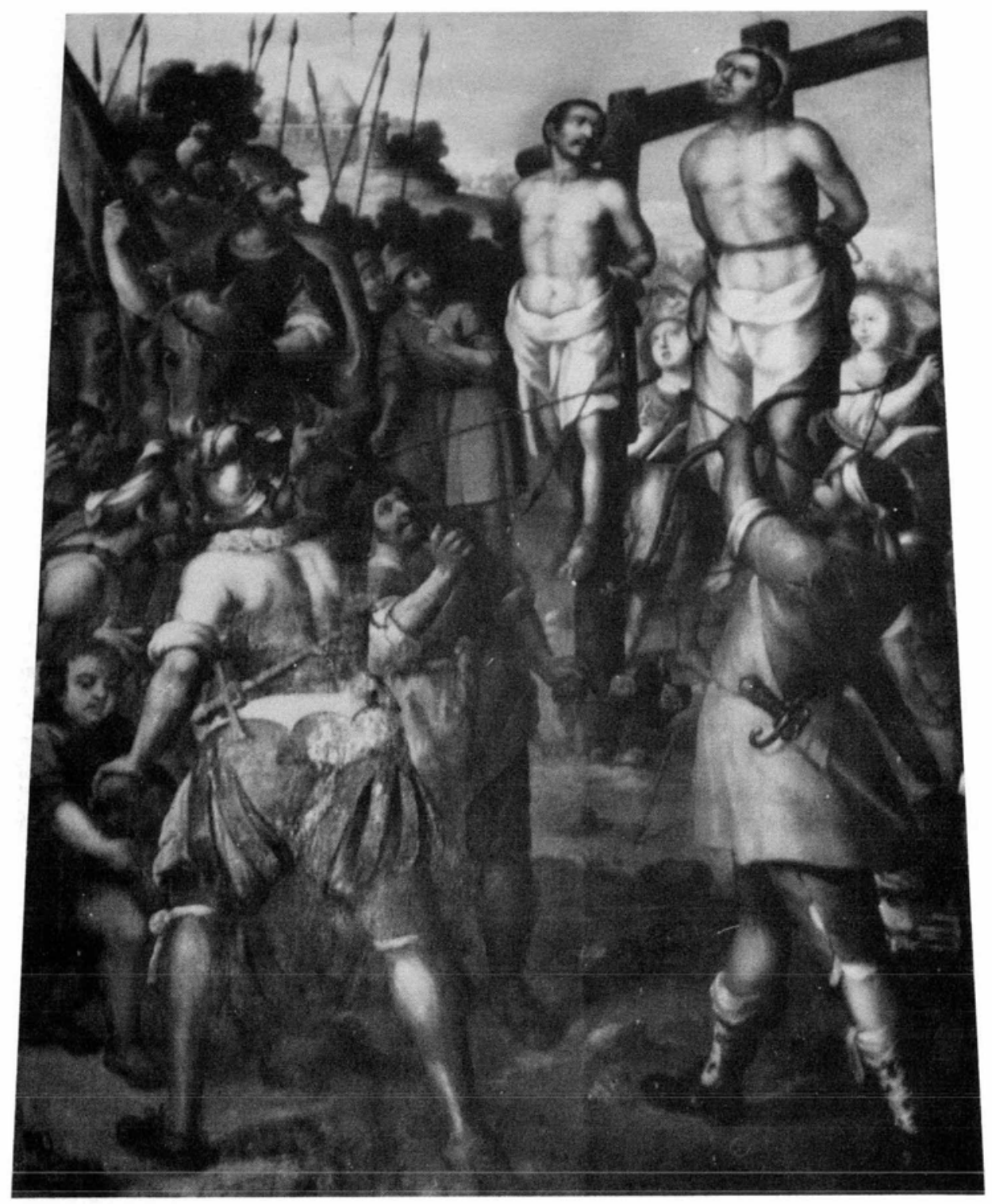

6. “Cosme y Damián salen indemnes del tormento de saetas y piedras”. 
DOI: http://dx.doi.org/10.22201/iie.18703062e.1993.64.1668

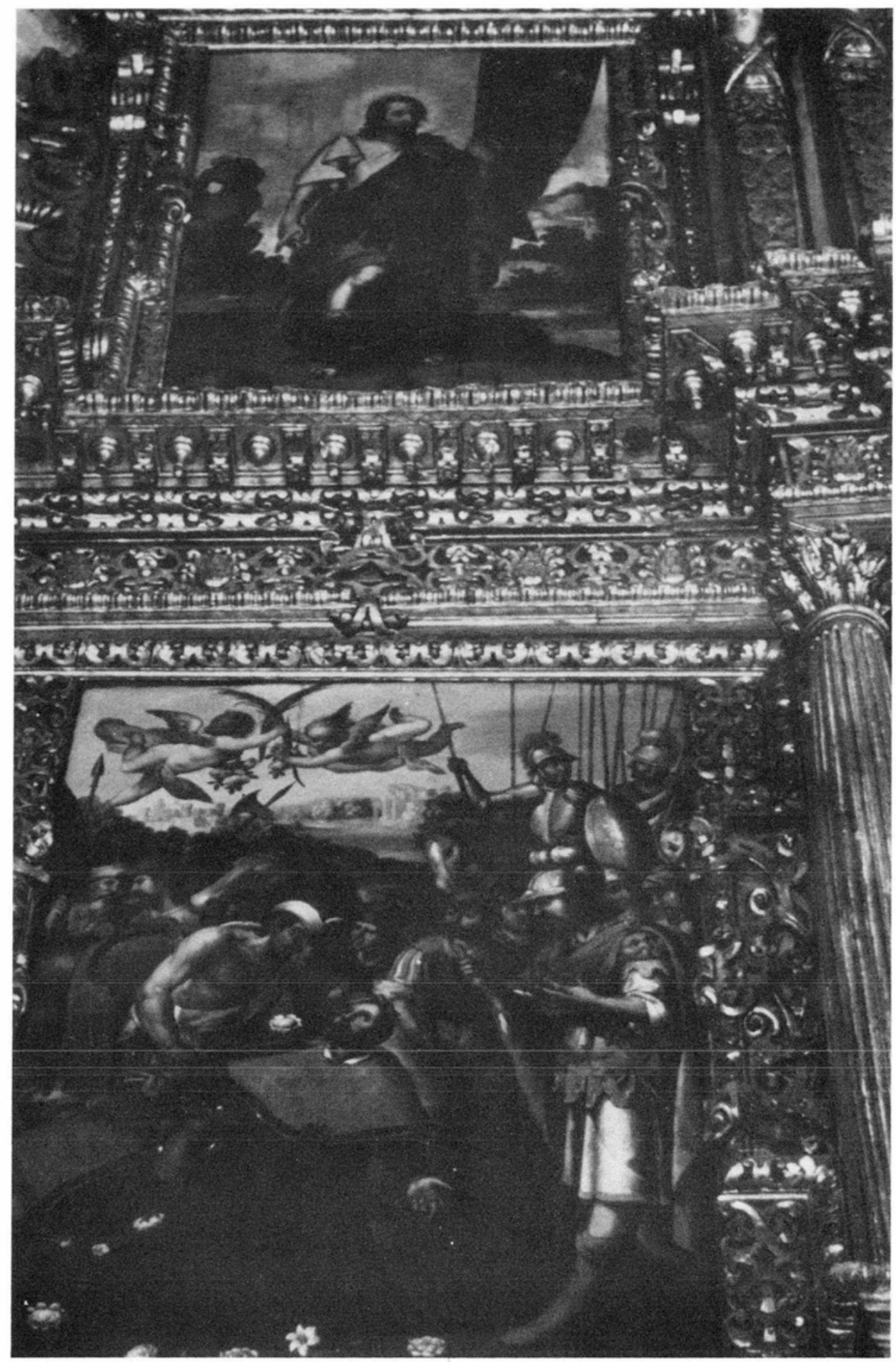

7. “Decapitación de Cosme y Damián”. Arriba "San Hipólito”. 


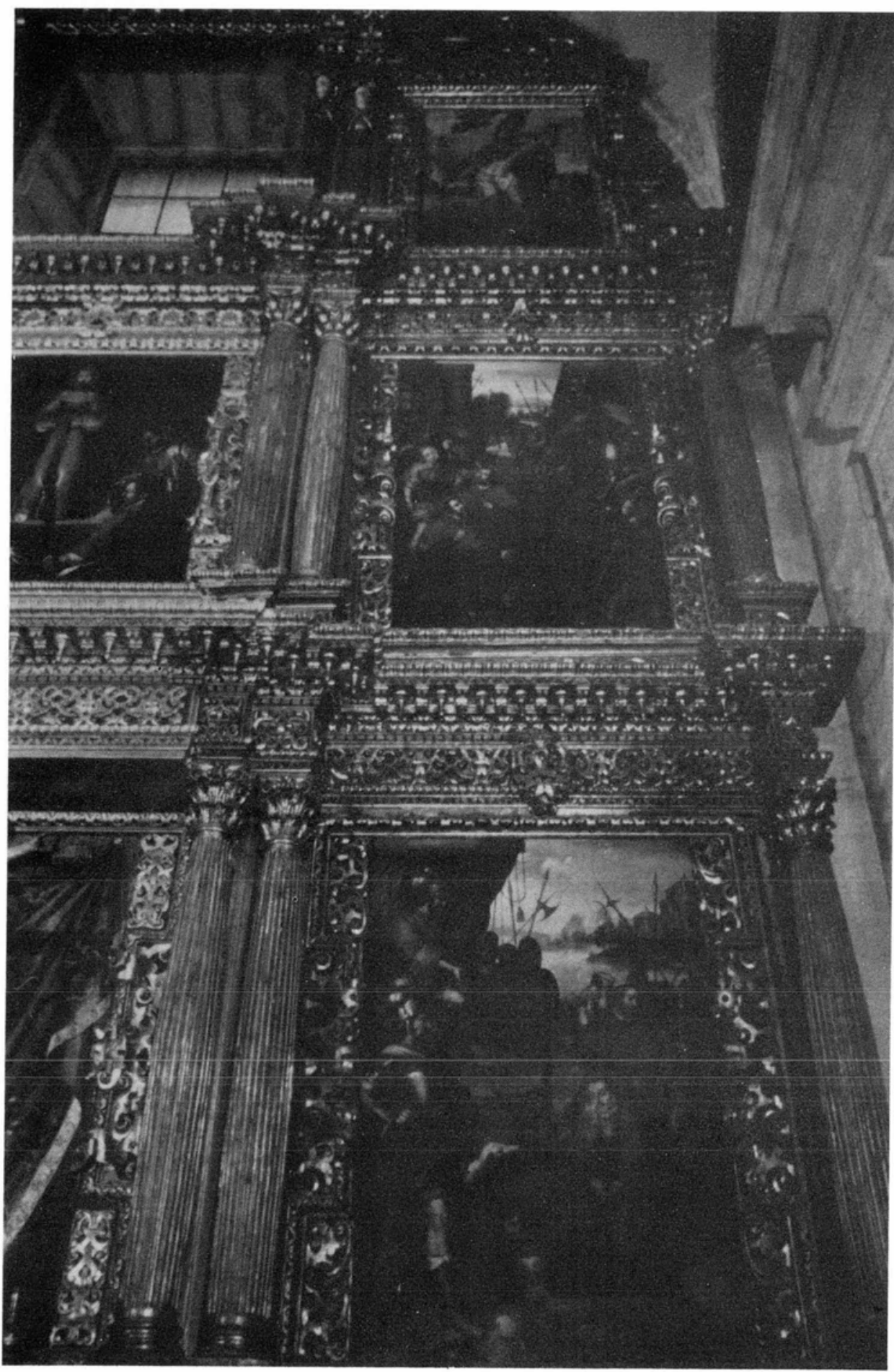

8. Pinturas de la calle del lado derecho. Arriba "San Sebastián". 


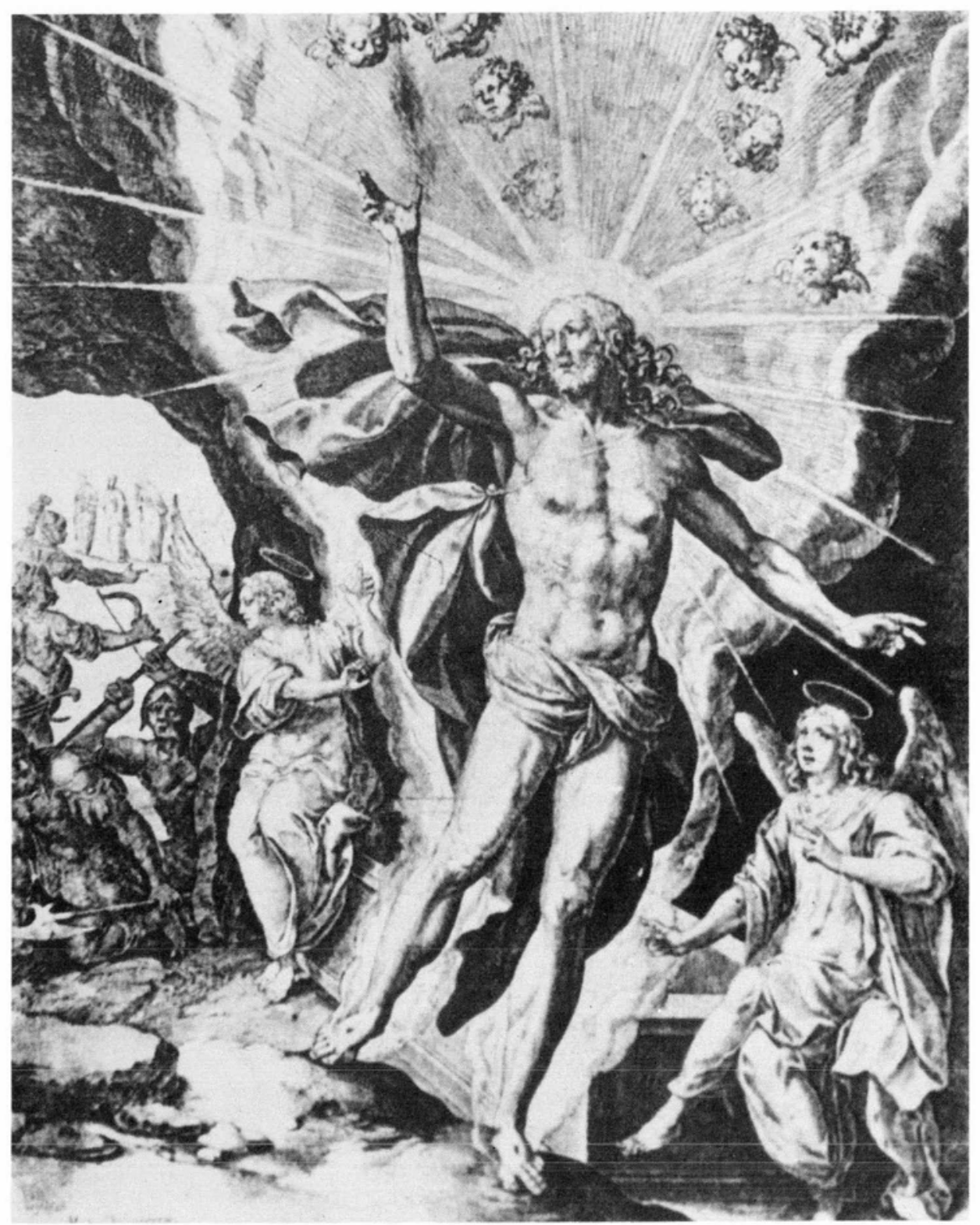

9. "Resurrección de Cristo", grabado de Jan Sadeler, a partir de un dibujo de Martín de Vos. 
santos hermanos titulares de la capilla. Dávalos le ha representado de pie, ante un árbol, con la mirada hacia lo alto, sosteniendo una flecha; está semidesnudo, cubierto con una capa roja y un lienzo blanco a la cintura. Tal pareciera que para la composición de su figura el pintor ha seguido-aunque invertida- la de Cristo según el grabado que representa la Resurrección ejecutado por Juan Sadeler a partir de un dibujo de Martín de Vos. ${ }^{44}$

El otro santo es San Hipólito. Ante un plácido paisaje, aparece de pie, vestido a la romana, enarbolando un pendón rojo, sobre el que se ve el águila parada sobre un nopal, que desde entonces se usaba, no como escudo pero sí como símbolo de la ciudad de México. Conviene recordar que en un 13 de agosto, día en que la Iglesia recuerda a este santo, Hernán Cortés ganó la ciudad mexica. ${ }^{45}$

La presencia de ambos mártires en este retablo obedece, al parecer, a que como Cosme y Damián, soportaron estoicamente varios tormentos antes de morir. Esto, aunado a la selección de los temas para los demás cuadros, pone de manifiesto que, más que pretender exaltar en Cosme y Damián sus dotes como médicos, se les ha enaltecido por su perseverancia en la fe y heroicidad en el martirio.

Por último, en el remate se ubica un pequeño medallón con el Padre Eterno $(75 \times 80 \mathrm{~cm})$. Éste no podía faltar, y como de costumbre, se le ha representado de busto, como asomándose y en actitud de bendecir.

En términos generales podemos reconocer en López Dávalos a un modesto pero nada despreciable pintor. Su dibujo no es mùy correcto, pero sí de gran firmeza, hasta el punto de que en zonas se antoja algo duro. Trabaja rostros que quieren ser expresivos, así como manos finas y gesticulantes. Ejecuta telas de factura aceptable aunque convencional, y sabe sugerir calidades y brillos metálicos. Pero quizá lo más atractivo de su pintura sea el jugoso colorido que emplea, en el que sobresalen los rojos, verdes, azules, rosas y amarillos, pero en el que hay cabida también para tonalidades violáceas, ocres y doradas.

Tiene dificultad para trabajar escorzos y no gusta de los intensos contrastes de luces y sombras; sin embargo, revela tener bien aprendida la lección

${ }^{44}$ Cfr. Francisco de la Maza, El pintor Martín de Vos en México, México, Universidad Nacional Autónoma de México, Instituto de Investigaciones Estéticas, pp. 58-59 e ilustración 29

${ }^{45}$ Actualmente se cree que san Hipólito exa un erudito sacerdote romano, uno de los más destacados escritores y teólogos de los primeros tiempos de la Iglesia, que murió en el destierro, en la isla de Cerdeña. Sin embargo, para el periodo colonial se aceptaba la conseja de que san Hipólito había sido un guardián romano que había sido convertido y bautizado por san Lor enzo, y que por ello se le había mandado azotar y condenado a ser arrastrado por dos briosos caballos; muerte que - cosa har to sospechosa- es justamente la que se cuenta tuvo Hipólito, el hijo de Teseo, en la mitología griega. Cfr. Alban Butler, op. cit., pp. 318-319. 
del claroscuro. En efecto, acorde a las resonancias del modo zurbaranesco que aún privan en la Nueva España para la época, Dávalos emplea la luz para dotar a los cuerpos y figuras de peso y volumen, pero también para sugerir diferentes planos de profundidad.

Los temas que ha desarrollado se prestaban para incluir fondos de paisaje, pero lo cierto es que nuestro artista revela notable sensibilidad y buen gusto en su empleo.

Con todo, para su época es un pintor un tanto retardatario, pues gusta de incluir figuras secundarias en poses de clara ascendencia manierista; véase, por ejemplo, la del soldado que se encuentra en primer plano en el cuadro en que aparecen los santos con las piedras de molino, o la del soldado de espaldas que también en un primer plano se encuentra en el cuadro en que el par de santos aparecen amarrados a las cruces. Algo de este espíritu manierista se advierte, asimismo, en el trazo de las figuras de san Sebastián y san Hipólito, y, en general, en el colorido y la iluminación.

Cabe señalar que, salvo en el cuadro en que están los hermanos amarrados en sus respectivas cruces y aparecen desnudos, en los demás visten amplios ropajes negros y la muceta de color amarillo - casi dorado- que es el color que correspondía a los que habían obtenido el grado académico de "doctor" en Medicina por la Real y Pontificia Universidad de México. ${ }^{46}$ También resulta interesante constatar que, en los dos cuadros de la predella, uno de ellos porta bonete con la borla blanca.

Para terminar, quisiera recordar lo que expresara don Manuel Toussaint sobre estos cuadros, obsservación que considero es la que más justicia hace a los mismos: "Son obras bastante bien logradas, muy características de esta época." ${ }^{47}$ El hecho de que éstas sean sus únicas obras conocidas, antes que restarles mérito las hace más atractivas e interesantes a nuestros ojos.

Tal y como vimos en su momento, los afamados artífices novohispanos Sebastián López de Arteaga y Pedro Ramírez, y acaso también Nicolás Becerra, le llevaron a bautizar tres hijos; padrino de otro hijo fue, asimismo, un descendiente de los Lagarto, la ilustre familia de iluminadores novohispanos del primer tercio de ese siglo xvi. Aunque datos aislados, no son hechos desprovistos de significación, por cuanto que nos dejan saber cuán pequeña y cerrada era la sociedad novohispana de la época, amén de

\footnotetext{
${ }^{46}$ Vid. Abelardo Carrillo y Gariel, El traje en la Nueva España, México, Instituto Nacional de Antropología e Historia, pp 193-194. Obsérvese que no visten simplemente trajes civiles ni los largos mantos rojos que suelen llevar en las representaciones del mundo europeo; $c f \gamma_{\text {. George }}$ Ferguson, Signos y simbolos en el arte cristiano, Buenos Aires, 1956, p. 163.

${ }_{47}$ Arte colonial en México, 2a. ed., México, Universidad Nacional Autónoma de México, Instituto de Investigaciones Estéticas, 1962, p. 117.
} 
que implican el establecimiento entre los hacedores del arte de un fuerte vínculo religioso -el "compadrazgo" - que iba más allá de las relaciones de trabajo y la simple amistad.

Si a lo anterior añadimos que López Dávalos gozaba de buen crédito ante sus colegas como para designarle su representante en el pleito que llevaban, y también sumamos el que explícitamente se reconocía su valía al designársele, junto con otros pintores, para hacer la inspección de la imagen de la Virgen de Guadalupe, el resultado es que era un pintor que ya se había labrado un nombre entre sus colegas y era respetado por sus contemporáneos.

Así las cosas, y pese al prestigio de que gozó en sus días, está claro que hoy, a la vista de sus únicos cuadros conocidos, nadie podría afirmar que Sebastián López Dávalos es un pintor de primera línea dentro del desarrollo de la pintura colonial mexicana. Sin embargo, no faltaríamos a la verdad si convenimos en que se trata de un artífice bastante interesante y nada despreciable de la segunda mitad del siglo xvi. En tanto que autor de una muy escasa producción, sólo queda esperar que el hallazgo de nuevas noticias y otras pinturas suyas vengan a enriquecer el conocimiento que tenemos de él y su obra. Por mi parte, considero con estas líneas haber contribuido a valorar de modo más justo su actuación en el quehacer pictórico de la Nueva España. 